\title{
Three cheers for the pain pump?
}

\author{
Jason L. Dragoo
}

Published online: 4 February 2015

(C) European Society of Sports Traumatology, Knee Surgery, Arthroscopy (ESSKA) 2015

Many of us remember the disastrous consequences of using local anaesthetics in intra-articular pain pumps. Thousands of young athletes, world wide, have had their athletic careers shortened due to pain from pain pump induced chondrolysis, and many subsequently required joint arthroplasty to alleviate their pain.

Initially, many pain pump companies in the USA were sued, for what was deemed inappropriate recommendations to surgeons to place the pain pump catheters within the joint. Only a small number of surgeons were successfully sued, as they demonstrated 'they were just trying to act in the best interest of their patient to decrease post-operative pain'.

Times have changed. There are now hundreds of articles available to surgeons that describe the risks of using local anaesthetics within the joint. The responsibility now lies with us to stay current with this literature and to appropriately use this class of medications. Litigation against physicians has recently skyrocketed, because attorneys have successfully argued that the physicians 'should have known which medications and delivery methods are safest, due to the numerous peer-reviewed articles in top-level journals such as Knee Surgery, Sports Traumatology, and Arthroscopy'.

J. L. Dragoo $(\bowtie)$

Department of Orthopaedic Surgery, Stanford University, 450

Broadway, Redwood City, CA 94063, USA

e-mail: jdragoo@stanford.edu
The following article by Breau et al. is a good example of this well-performed body of research. They have shown that short-term local anaesthetic exposure leads to increased cell death of human bone-marrow-derived mesenchymal stem cells. These results, along with other similar articles, indicate that immature stem cells may be more sensitive to the effects of local anaesthetics than more mature cells such as chondrocytes. This could have implications in regenerative medicine procedures such as microfracture, or in procedures using stem cells.

Although there are considerable conflicting results in this body of research, with some articles showing substantial injury to cells while others do not, there are a few conclusions that can be agreed upon. Most experts would agree that all local anaesthetics have some toxicity, but the degree of toxicity is most related to the concentration, volume used, and the duration of use of the medication. For example, if you have a choice to use 0.25 or $0.5 \%$ Marcaine post-operatively, it is likely safer to choose $0.25 \%$; and most would agree to use as little as possible, such as choosing $5 \mathrm{cc}$ rather than 10 .

Research has also identified some medications that appear to be considerably more toxic than others. This list includes local anaesthetics formulated with epinephrine [1] (although there does not appear to be any toxicity due to epinephrine alone) and the corticosteroid betamethasone (combinations of betamethasone sodium phosphate and betamethasone acetate) [2]. This toxicity may due to the preservative used or the $\mathrm{pH}$ levels contained within the preparations.

Perhaps, this whole pain pump ordeal has a sliver lining after all. Without it, all of the research on the effects of local anaesthetics on cartilage would not have been performed. But now we know more. We must continually educate ourselves, as we will be held to a higher 
standard regarding the type, concentration, and quantity of the local anaesthetic medications we inject into our patients.

Jason L. Dragoo, MD

Associate Professor

Stanford University

\section{References}

1. Dragoo JL, Korotkova T, Jagadish A (2010) Chondrotoxicity of low $\mathrm{pH}$, epinephrine, and preservatives found in local anesthetics containing epinephrine. Am J Sports Med 38(6):1154-1159

2. Dragoo JL, Danial CM, Braun HJ, Pouliot MA, Kim HJ (2012) The chondrotoxicity of single-dose corticosteroids. Knee Surg Sports Traumatol Arthrosc 20(9):1809-1814 